\title{
Optimal Design of a High-Speed Flux Reversal Motor with Bonded Rare-Earth Permanent Magnets
}

\author{
Vladimir Prakht (D), Vladimir Dmitrievskii (D) and Vadim Kazakbaev *(D) \\ Department of Electrical Engineering, Ural Federal University, 620002 Yekaterinburg, Russia; \\ va.prakht@urfu.ru (V.P.); vladimir.dmitrievsky@urfu.ru (V.D.) \\ * Correspondence: vadim.kazakbaev@urfu.ru; Tel.: +7-343-375-4507
}

check for updates

Citation: Prakht, V.; Dmitrievskii, V.; Kazakbaev, V. Optimal Design of a High-Speed Flux Reversal Motor with Bonded Rare-Earth Permanent Magnets. Mathematics 2021, 9, 256. https://doi.org/10.3390/math9030256

Academic Editor: Mario Versaci

Received: 12 December 2020

Accepted: 25 January 2021

Published: 28 January 2021

Publisher's Note: MDPI stays neutral with regard to jurisdictional claims in published maps and institutional affiliations.

\begin{abstract}
Single-phase flux reversal motors (FRMs) with sintered rare-earth permanent magnets on the stator for low-cost high-speed applications have a reliable rotor and a good specific power. However, to reduce eddy current loss, the sintered rare-earth magnets on the stator have to be segmented into several pieces and their cost increases with the number of magnet segments. An alternative to the sintered magnets can be bonded magnets, in which eddy current loss is almost absent. The remanence of bonded magnets is lower than that of sintered magnets, and they are prone to demagnetization. However, the cost of low-power motors with bonded magnets can be lower because of the simpler manufacturing technology and the lower material cost. This paper discusses various aspects of the optimal design of FRM with bonded magnets, applying the Nelder-Mead method. An objective function for optimizing an FRM with bonded magnets is designed to ensure the required efficiency, reduce torque oscillations, and prevent the bonded magnets from demagnetizing. As a result, it is shown that the FRM with bonded magnets has approximately the same efficiency as the FRM with sintered magnets. In addition, the peak-to-peak torque ripple is minimized and the minimal instantaneous torque is maximized.
\end{abstract}

Keywords: demagnetization; electric machine; flux reversal machine; high-speed electrical machine; high-speed electrical motor; Nelder-Mead method; optimal design

\section{Introduction}

Single-phase variable-speed motors are widely used in low-cost applications such as vacuum cleaners [1], blowers [2], power tools [3], pumps [4], compressors [5], and fans [6]. The main advantage of single-phase motors is the lower cost of the semiconductor inverter that has fewer transistors than in the case of a three-phase motor.

In turbochargers, vacuum cleaners, blowers, and other high-speed applications, a retaining ring on the rotor of such a brushless motor is used to provide strength against centrifugal forces and to increase its reliability. However, this also increases the cost of the rotor and its complexity. In addition, applying a retaining ring also increases the equivalent air gap, i.e., the gap between the rotor magnets and the stator teeth. This reduces the specific torque and efficiency [7].

Therefore, in low-cost high-speed applications, it can be preferable to use motors with a simple and reliable toothed rotor and with magnets on the stator, such as flux switching motors (FSMs) [8,9], flux reversal motors (FRMs) [10,11], or hybrid switched reluctance motors (HSRMs) [12,13]. Applying a structurally simple toothed rotor made of a steel lamination reduces the cost of rotor manufacturing in comparison with a rotor with magnets on its surface and with a retaining ring [14] and also increases the reliability of the motor. However, to reduce eddy current loss, the sintered rare-earth magnets on the stator have to be segmented into several pieces $[10,11,15]$. The cost of the magnets increases with the number of magnet segmentations [16,17].

An alternative to rare-earth sintered magnets can be bonded magnets, in which eddy current loss is almost absent. The remanence of bonded magnets is lower than that of 
sintered rare-earth magnets, but the cost of low-power motors with bonded magnets is lower compared to motors with sintered rare-earth magnets because of the simpler manufacturing technology and also the lower material cost [18-20]. For this reason, the use of motors with bonded magnets is also prospective in low-cost applications. Therefore, the aim of this work is to optimize a single-phase FRM with bonded magnets to use in low-cost high-speed applications.

The optimization of motors with bonded magnets on the rotor is considered in [21-23]. An evolutionary approach is applied in [21]. A hand-made optimization is performed in [22]. A quasi-Newtonian technique is used in [23]. However, optimization of a singlephase FRM with bonded magnets has not been considered yet.

When designing electrical machines, multi-criteria optimization methods are extensively used [24-26]. Such methods can create a Pareto front that includes solution points in which no objective can be improved without degrading others. Then, from all points of the obtained Pareto front, one point is manually selected, the characteristics of which most satisfy the solution of a given technical problem. Typically, multi-criteria methods require a substantial number of function calls. For example, in [24], about 3000 calls are required.

A one-criterion method can also be applied to the problem of optimization of electric machines. In this case, the objective function is constructed with a number of multipliers, each of which is an expression of a separate criterion. The importance of each multiplier can be adjusted when constructing such a function. Therefore, if, in the case of the Pareto approach, the final design is chosen among the points of a Pareto front after the optimization process to satisfy the practical importance of each of the optimization criteria, in the case of a one-criterion method, it is necessary to determine the importance before the start of the optimization process. However, the use of one-criterion methods allows a significant reduction in computational time. For example, in [10], the Nelder-Mead method was applied and only 115 function calls were required, which is 26 times less than in [24], when a multi-criteria method was applied.

It can be concluded that although the Nelder-Mead method does not provide confidence in finding the global optimums according to the Pareto criterion, it significantly reduces the computational time and can provide good practical results.

In this work, a multi-criteria product-type optimization function was built and the one-criterion Nelder-Mead method was applied to reduce the calculation time.

The Nelder-Mead method has previously been successfully applied to optimize various types of electrical machines using various objective functions [10,11,14,27,28]. In each of these works, a special objective function was constructed which depends on the specifics of an electrical machine and application. In [28], optimization of a synchronous reluctance motor was considered by applying this method. A motor efficiency much higher than the IE5 level ("ultra premium efficiency") according to the IEC (International Electrotechnical Commission) 60034-30-2 standard was reached. Torque ripple and underload efficiency also were improved. In [11], optimization of a single-phase high-speed FRM with sintered rare-earth magnets was carried out to reduce torque oscillations and power loss when operating with a fan load profile.

However, the optimization criterion developed for an FRM with sintered rare-earth magnets [11] cannot be applied to an FRM with bonded magnets, since in this case, there is a risk of demagnetization of bonded magnets. This paper discusses various aspects of the optimal design of FRMs with bonded magnets applying the Nelder-Mead method. An objective function for optimizing the FRM with bonded magnets is designed to ensure at least $84 \%$ efficiency, reduce torque oscillations, and prevent the bonded magnets from demagnetizing.

\section{Construction of an Objective Function for Single-Phase Flux Reversal Motor with Bonded Permanent Magnet}

In [11], the optimization of a 754-W, 18-krpm single-phase FRM with segmented sintered rare-earth magnets $(\mathrm{NdFeB})$ is considered for fan load (the torque is proportional 
to the square of the rotational speed). Table 1 determines 2 considered loading modes of the motor range.

Table 1. Loading points of the flux reversal motor (FRM).

\begin{tabular}{ccccc}
\hline Mode Number & Torque, N·m & $\begin{array}{c}\text { Rotational } \\
\text { Speed, rpm }\end{array}$ & $\begin{array}{c}\text { Rotational } \\
\text { Speed, } \%\end{array}$ & $\begin{array}{c}\text { Mechanical } \\
\text { Power, W }\end{array}$ \\
\hline 1 & 0.256 & 14,400 & 80 & 386 \\
2 & 0.4 & 18,000 & 100 & 754 \\
\hline
\end{tabular}

Considering that the portion of time taken by a particular loading mode is supposed to be approximately inversely proportional to active (real) power, the arithmetic average efficiency in the two modes $(\langle\eta>)$ was chosen in [11] as one of the optimization objectives of the FRM with sintered rare-earth magnets. The efficiency of the FRM with sintered rare-earth magnets is $85.7 \%$ in mode 1 and $84.5 \%$ in mode 2 . The average efficiency is $<\eta>=85.1 \%$ in this case.

In addition to the efficiency, other objectives for optimizing the FRM with sintered rare-earth magnets described in [11] are:

1. Maximizing the minimum instantaneous value of the torque waveform and making it positive if it is possible.

2. Reducing the peak-to-peak value of torque ripple (PPTR).

To achieve both of these objectives using the Nelder-Mead method, the optimization criterion was formulated as $A=\langle P P T R+2 \cdot A M i n T D>$, where $A M i n T D$ is the average to minimum torque difference; " $<>$ " is the sign of the arithmetic mean over both loading modes considered. Therefore, the following optimization function was applied in [11] to the FRM with sintered rare-earth magnets:

$$
F=A \cdots B=<P P T R+2 \cdot A M i n T D>(1-<\eta>),
$$

Modern sintered rare-earth magnets not only have high remanence but are also highly coercive magnets. In Gaussian units, the coercivity of such magnets can be 2 or more times higher than their remanence. For this reason, the risk of demagnetization was not taken into account in the objective function when optimizing the FRM with sintered rare-earth magnets in [11]. The modern bonded magnets have significantly lower remanence than sintered rare-earth magnets, which leads to an increase in the required magnetomotive force of the winding (MMF) and, therefore, to the risk of demagnetization. In addition, the coercivity of bonded magnets is much lower than that of sintered rare-earth magnets. Therefore, when designing FRMs with bonded magnets, it is necessary to consider the risk of demagnetization. Bonded magnets of 3210 grade $\left(B_{r}=7 \mathrm{kG}, H_{c i}=9.5 \mathrm{kOe}\right)$ [29] were chosen for the FRM.

The main objective in this study was also to minimize the torque oscillations (term $A$ in [1]) of the FRM with bonded magnets. In addition, the average efficiency of the motor must be at least $84 \%$ (i.e., approximately the same value as in [11]) and the risk of demagnetizing the bonded magnets must be avoided. It was assumed that the demagnetizing magnetic field must not exceed the coercivity by more than $0.3 \%$ of the total volume of the magnets.

The unconstrainted one-criterion Nelder-Mead method is applied in this study to optimize the FRM design. The Nelder-Mead method belongs to unconstrained optimization methods. Therefore, there is no need to set the permissible range of parameters before the optimization. It is necessary to determine only the initial design and the objective function. The noise of the objective functions is caused, firstly, by rounding errors of the finite element method and, secondly, by differences in the mesh that is rebuilt with each different call of the objective function.

It is possible to compose an objective function that takes the value $A$ if $\langle\eta\rangle$ is more than $84 \%$ and the volume of the demagnetized magnets is less than $0.3 \%$ and goes to infinity otherwise. However, first, the initial set of design parameters may not satisfy the 
formulated constraints, and the optimization direction cannot be determined. Second, whenever these conditions are not satisfied, the size of the simplex constructed by the Nelder-Mead algorithm decreases, and this will slow down the search for the optimum.

In this work, instead of processing the constraints precisely, an objective function with soft constraints is adopted; that is, penalty factors increasing rapidly if the constrained characteristics of the machine go beyond the specified limits are added to the optimization function [30]. In the considered case, the second factor will increase exponentially if the average efficiency becomes less than 0.84 , and the third factor will increase exponentially if the volume of demagnetized magnets becomes greater than $0.3 \%$ :

$$
F=A\left(1+e^{\delta_{1}(0.84-<\boldsymbol{\eta}>)}\right)\left(1+e^{\delta_{2}(\max (S)-0.003)}\right)
$$

where $\eta$ is the motor efficiency; $S$ is the volume part of the demagnetized magnets; max is the maximum value among the loading modes considered. In addition to the first factor $A$, expression (2) contains two other factors. The second factor grows rapidly at $<\eta><0.84$ and rapidly tends to unity at $<\eta>>0.84$. The third factor grows rapidly at $\max (S)>0.003$ and rapidly tends to unity at $\max (S)<0.003$. Multipliers $\delta_{1}=200$ and $\delta_{2}=3000$ set the slope of $F$. Both exponents equal to 1 at $<\eta>=0.84$ and $\max (S)=0.003$. The exponent in the first multiplier becomes equal to $e$ when $\langle\eta>$ increases by $0.5 \%$. The exponent in the second multiplier becomes equal to $e$ when $\max (S)$ increases by 0.00033 , which is $11 \%$ of its reference value 0.003 .

\section{Initial Design and Parameters Varied During Optimization}

Figure 1 demonstrates the main geometric parameters of the FRM with bonded magnets. As in the case of the FRM with sintered magnets, there are two poles on the surface of each stator tooth; there is the same direction of magnetization of adjacent magnetic poles on adjacent stator teeth. In contrast to sintered magnets, the segmentation of the magnets is not required in the case of bonded magnets. Therefore, the pole pair placed on each tooth can be formed by, for example, one two-pole magnet, which simplifies the production of the rotor assembly and reduces the cost. Here, 35PN440 electrical steel with a thickness of $0.35 \mathrm{~mm}$ [31] was selected to determine the properties of the stator and rotor laminations.

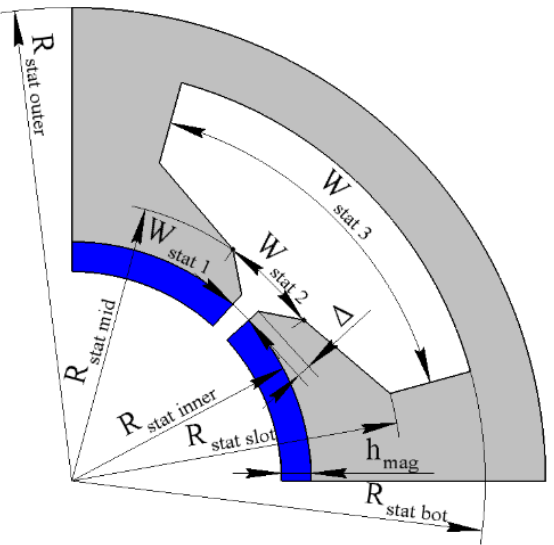

(a)

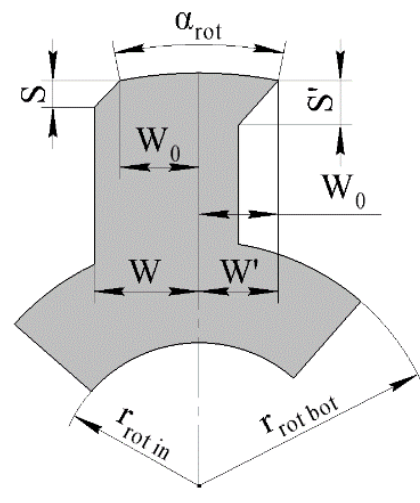

(b)

Figure 1. Design parameters of the FRM: (a) stator; (b) rotor.

Table 2 shows the design parameters varied during the optimization of the FRM with bonded magnets: the number of turns per phase; outer stator radius $R_{\text {stat, inner; }}$ stator slot dimensions $R_{\text {stat, inner, }}, R_{\text {stat }, \text { bottom }}$ and $W_{\text {stator } 1}$; rotor dimensions $\alpha_{\mathrm{rot}}, w / w_{0}, w^{\prime} / w_{0}$, and shifting angle of the supply voltage. Furthermore, $R_{\text {stat, middle }}=0.5 \cdots\left(R_{\text {stat }, \text { slot }}+R_{\text {stat,inner }}\right)$. 
Table 2. Parameters that changed during the optimization.

\begin{tabular}{ccc}
\hline Parameter & Before & After \\
\hline Number of turns per phase & $80-10$ & 111 \\
$R_{\text {stat }, \text { inner }}, \mathrm{mm}$ & $18+1$ & 19.2 \\
$R_{\text {stat }, \text { slot }}, \mathrm{mm}$ & $22+1$ & 23.8 \\
$R_{\text {stat }, \text { bottom }}, \mathrm{mm}$ & $26+1$ & 28.3 \\
$W_{\text {stator } 1}$, degrees & $12.6+1.8$ & 12.5 \\
$\alpha_{\text {rot, }}$ degrees & $27-4.5$ & 22.9 \\
$w / w_{0}$ & $1.5-0.2$ & 1.78 \\
$W^{\prime} / w_{0}$ & $0.8+0.2$ & 0.72 \\
Voltage shift, electrical radians & $0.015+0.01$ & 0.033 \\
\hline
\end{tabular}

In the beginning, the Nelder-Mead algorithm constructs the initial simplex and calculates the value of the objective function in each point of this simplex. In the MATLAB function "fminseach", to define points of the simplex, each parameter of the initial design, in turn, increases by $5 \%$. Such an approach has some disadvantages. First, changing some parameters by $5 \%$ can lead to a very significant change in the objective function, but not for others. Changing various parameters by $5 \%$ can affect the change in the objective function to a very different extent.

Table 3 shows the parameters that did not vary during the optimization.

Table 3. Parameters that were fixed during the optimization.

\begin{tabular}{cc}
\hline Parameter & Value \\
\hline Supply voltage, $\mathrm{V}$ & 320 \\
Stator stack length $L, \mathrm{~mm}$ & 30 \\
Stator outer radius, $R_{\text {stat_outer }}, \mathrm{mm}$ & 32 \\
Stator slot width $W_{\text {stat } 3 \text {, degrees }}$ & 72.9 \\
Stator slot width $W_{\text {stat } 2, \text { degrees }}$ & 36.5 \\
$\Delta$, mm & 0.007 \\
Magnet thickness, mm & 2 \\
Air gap, mm & 0.5 \\
Magnet's remanence, $\mathrm{T}$ & 0.65 \\
S, mm & 2 \\
$S^{\prime}, \mathrm{mm}$ & 3 \\
$R_{\text {rot bot }}, \mathrm{mm}$ & 7 \\
$R_{\text {inr }}, \mathrm{mm}$ & 3 \\
\hline
\end{tabular}

For example, an increase in $R_{\text {stat, bottom }}$ by only $5 \%$ causes a significant decrease in the stator yoke thickness and, therefore, can lead to a significant change in saturation level, while an increase in $\alpha_{\text {rot }}$ by $5 \%$ does not lead to a significant change in the performance. Of course, it is possible to try to select the parameters in such a way so as to avoid this problem. For example, the thickness of the yoke can be used instead of $R_{\text {stat }, \text { bottom }}$. However, it is more convenient to set the increment for each parameter separately. Second, with an increment in a certain parameter when constructing the next point of the simplex, the objective function may accidentally decrease. Then, having a more optimal design, it is not reasonable to increase the next parameter of the initial design. Therefore, in this study, augmentation of the next parameter is performed for the best design from the already constructed points of the simplex. Thus, in this work, the simplest optimization is carried out already at the stage of constructing a simplex. To construct a simplex, an initial design is first calculated. Then, at each step, the best of the calculated points is selected, and the next parameter is changed. The procedure continues until the number of points of the simplex is one more than the number of parameters.

Therefore, the procedure of building the simplex is as follows:

1. The array $x$ of the initial design parameters and the array $d$ of their increments are given. 
2. $\quad F_{\min }=F(x) \cdot x_{\min }=x$. Simplex $=\{x\}$.

3. For $i$ from 1 to $n$ (where $n$ is the number of parameters):

a. $x=x_{\min }$.

b. $\quad x(i)=x(i)+d(i)$.

c. $\quad$ Simplex $=$ Simplex $\cap\{x\}$.

d. If $F(x)<F_{\min }$, then $x_{\min }=x, F_{\min }=f(x)$.

After the simplex was built, the Nelder-Mead algorithm, as it is described in [32], was applied. The reflection, expansion, and contraction coefficients are 1,2 , and $\frac{1}{2}$, respectively.

\section{Optimization Results of FRM with Bonded Permanent Magnets and Discussion}

The Nelder-Mead algorithm, described in [32], was used in designing a new FRM with bonded magnets. The number of optimization parameters was nine. The mathematical model described in [33] was used to evaluate the objectives $\langle\eta\rangle$ and $\max (S)$ included in the optimization function (2).

Figure 2 shows the FRM designs and the flux density magnitude plots before and after the optimization. An asymmetrical rotor was chosen for the FRM since it was shown in $[11,14]$ that such a rotor design provides positive values of the torque waveform during the entire period, in contrast to a symmetrical rotor.

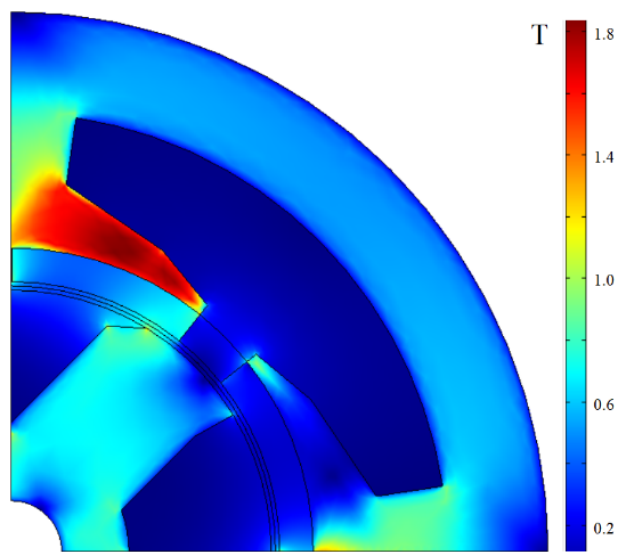

(a)

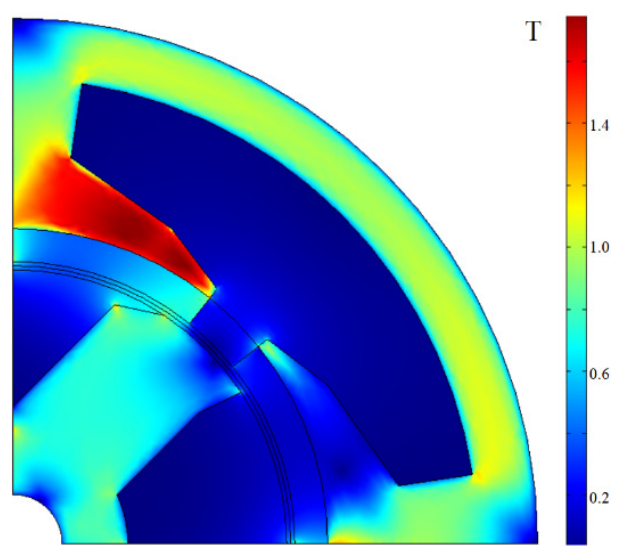

(b)

Figure 2. Calculation area arrangement and flux density magnitude plot (T) in the FRM (a) before optimization and (b) after.

Table 2 shows the variable design parameters of the FRM before and after the optimization. Next to the initial value of the variable parameter, its increment at constructing the initial simplex is given. As seen in Table 2 and Figure 2, the maximum flux density decreased as a result of optimization. In addition, the thickness of the yoke, which was underutilized in the initial design, was reduced, which increased the flux density in the yoke. It made it possible to increase the value of $R_{\text {stat, inner }}$. Figure 3 shows the dependence of the torque on the rotor angular position before and after optimization for two loading modes of the FRM with bonded magnets. Figures 4 and 5 demonstrate the waveforms of the current and voltage depending on the rotor angular position before and after optimization for two loading modes of the FRM with bonded magnets. PPTR and AMinTD changed only slightly. This is because the initial design was obtained by scaling the design of the optimized FRM with sintered rare-earth magnets [11]. 


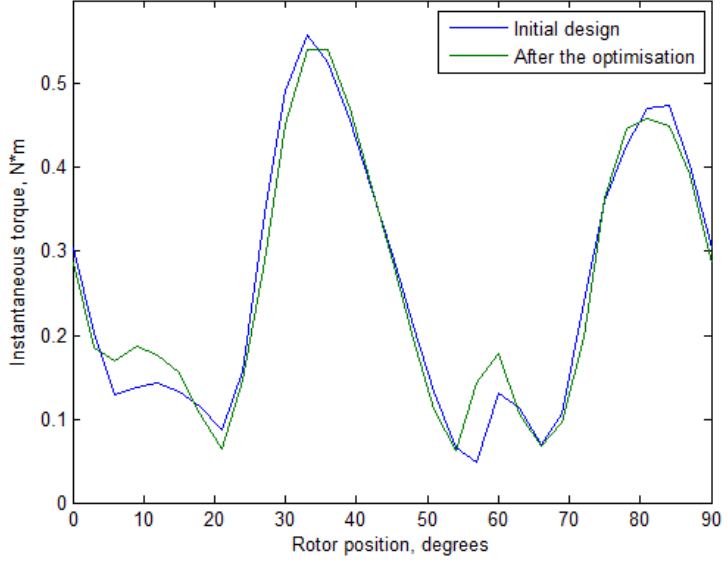

(a)

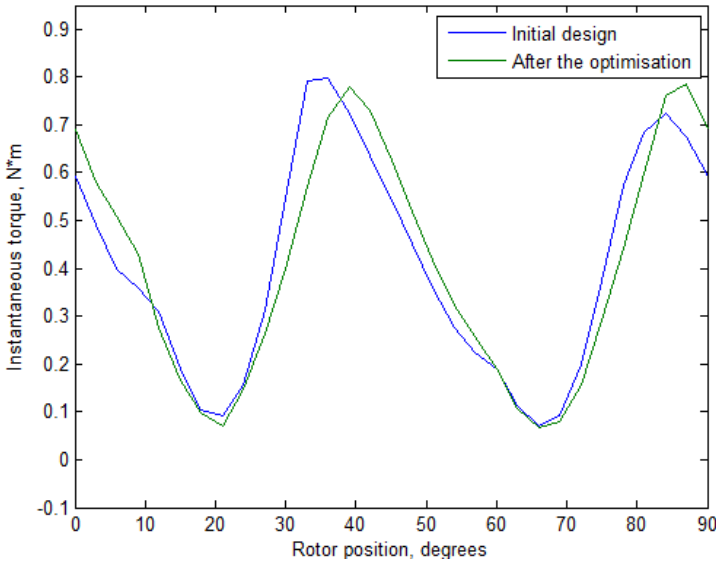

(b)

Figure 3. Torque waveforms versus the rotor angular position before and after the optimization: (a) mode 1 ; (b) mode 2 .

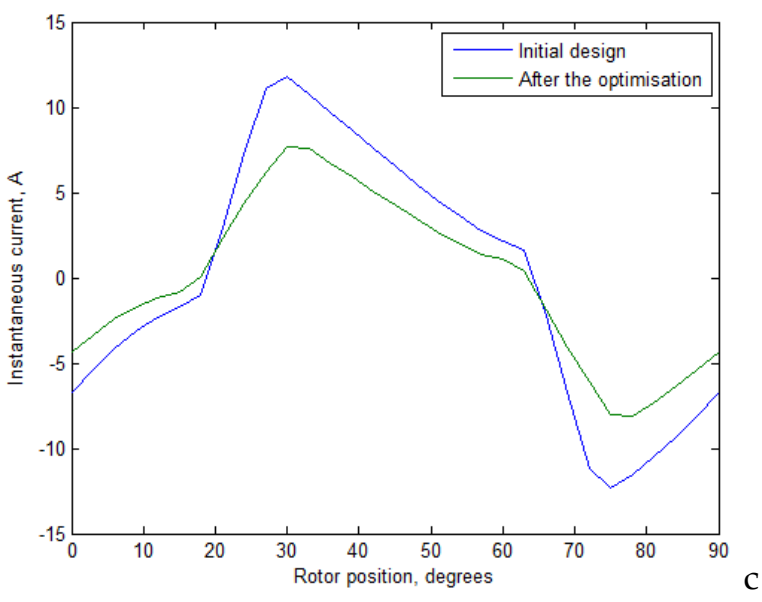

(a)

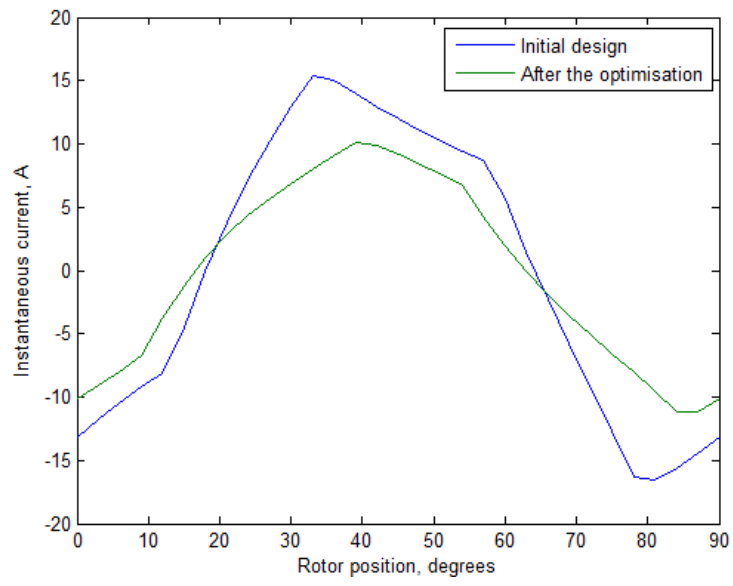

(b)

Figure 4. Current waveforms versus the rotor angular position before and after the optimization: (a) mode 1; (b) mode 2.

Figure 5 shows the dependence of the voltage on the rotor position. The voltage waveform is rectangular. The discretization that leads to the non-rectangularity of this voltage waveform on the plots is clearly visible. The motor torque is controlled by adjusting the voltage duty cycle. The more torque (mechanical power) that is required, the longer the duty cycle. After optimization, the duty cycle increased in both considered loading modes, taking the optimal values. This is achieved, in particular, by increasing the number of turns. With increasing the number of turns, the current decreased, as can be seen in Figure 4 .

Figure $6 \mathrm{~b}$ shows the dependence of the objective function on the number of the function calls. The very large values of the objective function at the beginning of the optimization process are not shown on the plot for better visibility of small changes in the objective function.

Figure 6a shows this dependence at the stage of constructing the simplex. The value of the objective function corresponding to the initial design is 6.84 . Already at the stage of constructing the simplex, it was possible to find an improved design with an objective function value of 1.77. This improvement was achieved by fulfilling the soft constraints on the motor efficiency and the volume of the demagnetized magnets. Figure $7 \mathrm{a}$ shows the change in average efficiency during optimization. Figure $7 \mathrm{~b}$ shows the variation in the motor torque oscillations $A$ during optimization. Figure 8 a shows the change in the volume percentage of demagnetized magnets during optimization. Figure $8 \mathrm{~b}$ shows the comparison of the motor losses at two considered operating points before and after optimization. Table 4 shows the characteristics of the FRM before and after optimization. 


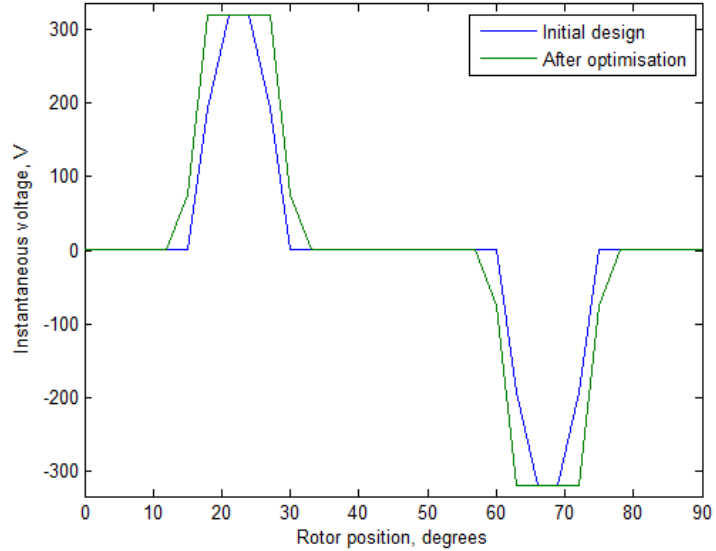

(a)

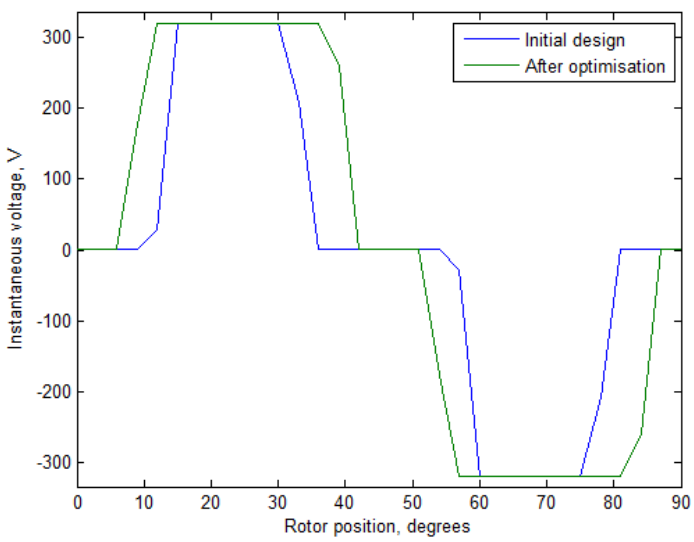

(b)

Figure 5. Voltage waveforms versus the rotor angular position before and after optimization: (a) mode 1; (b) mode 2.

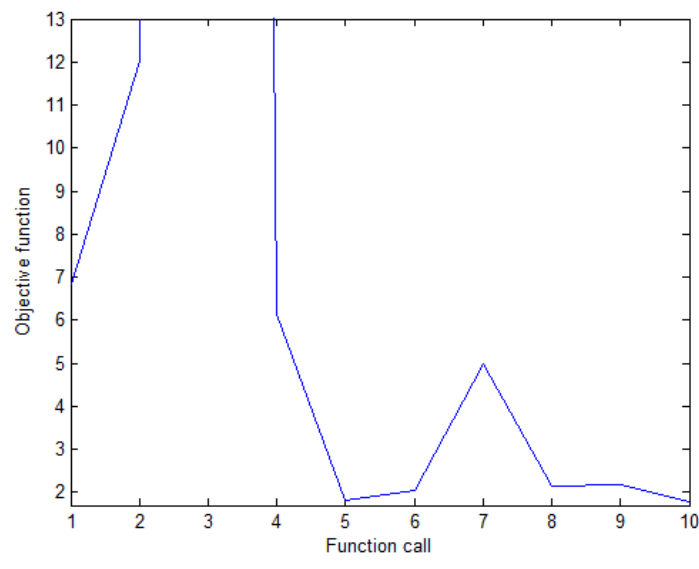

(a)

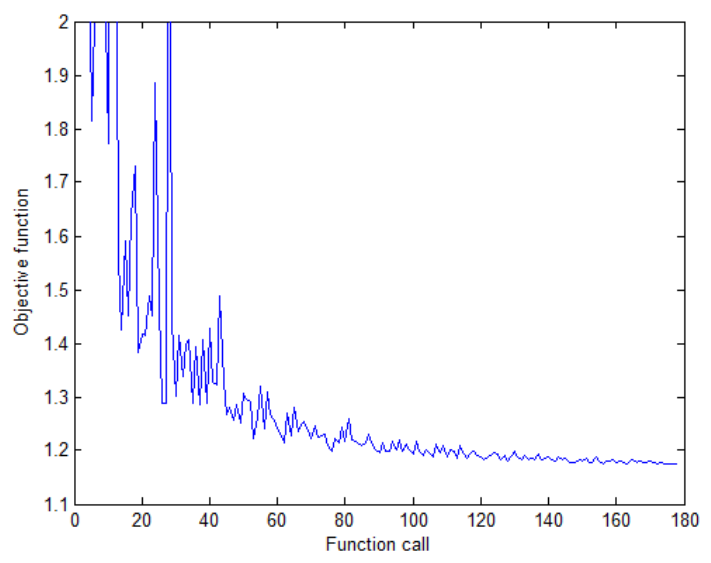

(b)

Figure 6. The objective function change during building of the simplex (a) and during the optimization (b). Different scales in plots $(\mathbf{a}, \mathbf{b})$ are chosen to better show the change in the objective function when building the initial simplex.

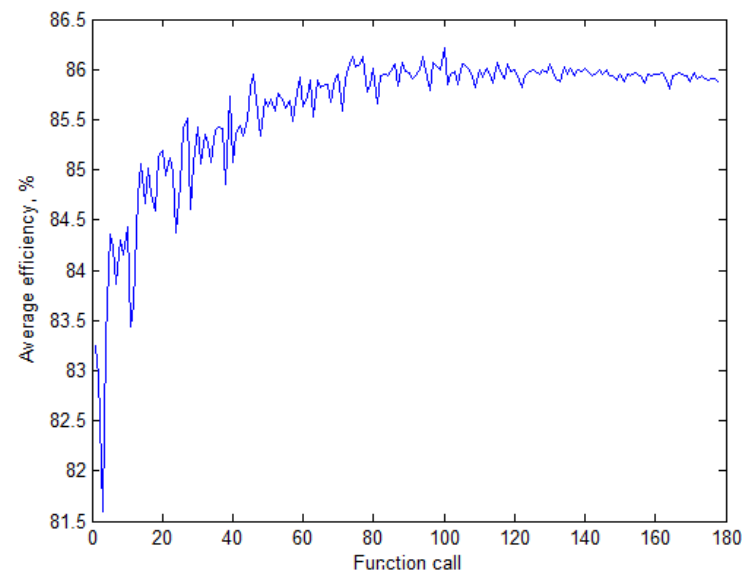

(a)

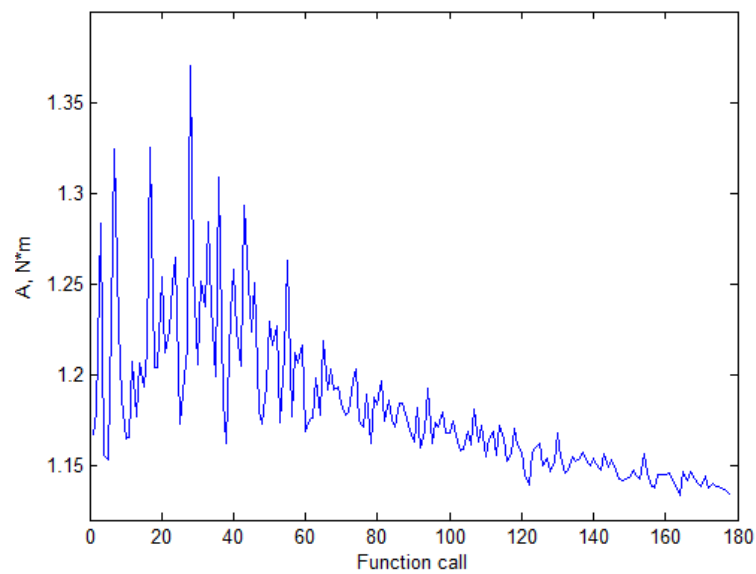

(b)

Figure 7. (a) Variation of the average efficiency during the optimization; (b) variation of the torque oscillations during the optimization. 


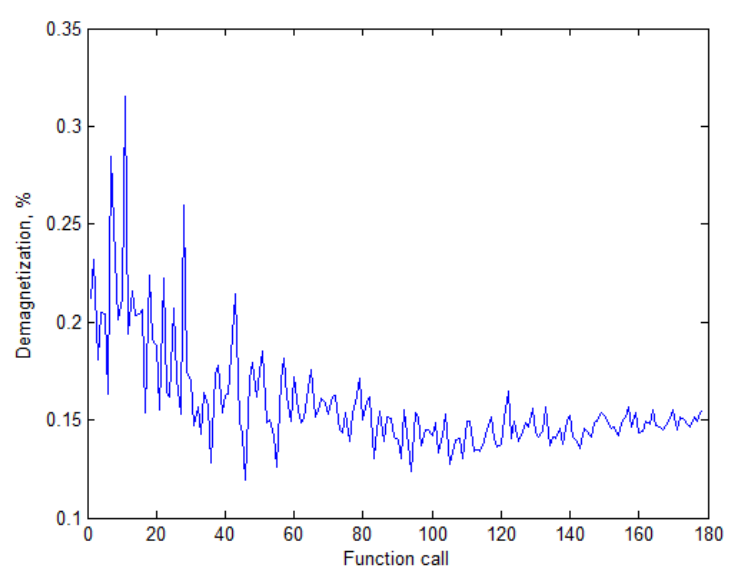

(a)

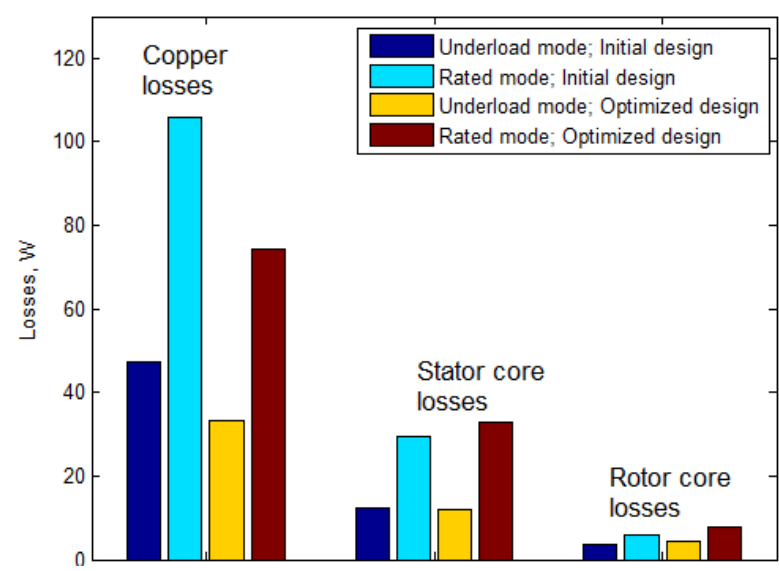

(b)

Figure 8. (a) Variation of the demagnetization percentage during the optimization; (b) losses of both FRMs in two modes.

Table 4. The FRM characteristics before and after optimization.

\begin{tabular}{|c|c|c|c|c|}
\hline \multirow{2}{*}{$\begin{array}{c}\text { Parameter } \\
\text { Rotational speed, rpm }\end{array}$} & \multicolumn{2}{|c|}{ Before Optimization } & \multicolumn{2}{|c|}{ After Optimization } \\
\hline & 14,400 & 18,000 & 14,400 & 18,000 \\
\hline Electric frequency, $\mathrm{kHz}$ & 0.96 & 1.2 & 0.96 & 1.2 \\
\hline Current, A (RMS) & 7.3 & 11 & 4.8 & 7.2 \\
\hline Efficiency, \% & 83.9 & 82.6 & 86.6 & 85.2 \\
\hline Total losses, W & 72.2 & 156 & 58.2 & 128.5 \\
\hline Mechanical power, $\mathrm{W}$ & 386 & 754 & 386 & 754 \\
\hline Electric power, $\mathrm{W}$ & 449 & 895 & 435 & 868 \\
\hline Duty cycle & 0.213 & 0.449 & 0.3 & 0.69 \\
\hline $\begin{array}{l}\text { Minimal instantaneous torque, } \\
\mathrm{N} \cdot \mathrm{m}\end{array}$ & 0.048 & 0.07 & 0.063 & 0.068 \\
\hline AMinDT, $\mathrm{N} \cdot \mathrm{m}$ & 0.21 & 0.33 & 0.193 & 0.33 \\
\hline PPTR, N·m & 0.510 & 0.729 & 0.479 & 0.718 \\
\hline$A, \mathrm{~N} \cdot \mathrm{m}$ & \multicolumn{2}{|c|}{1.16} & \multicolumn{2}{|c|}{1.12} \\
\hline$P P T R, \%$ of the average value & 199 & 182 & 187 & 180 \\
\hline Magnets deterioration, \% & 0.056 & 0.21 & 0.059 & 0.15 \\
\hline Stator core mass, $\mathrm{g}$ & \multicolumn{2}{|c|}{340} & \multicolumn{2}{|c|}{260} \\
\hline Rotor core mass, g & \multicolumn{2}{|c|}{96} & \multicolumn{2}{|c|}{105} \\
\hline Magnets volume, $\mathrm{cm}^{3}$ & \multicolumn{2}{|c|}{5.5} & \multicolumn{2}{|c|}{5.9} \\
\hline Copper mass, $\mathrm{g}$ & \multicolumn{2}{|c|}{239} & \multicolumn{2}{|c|}{295} \\
\hline
\end{tabular}

It can be seen from Table 4 that a design that does not satisfy the optimization constraints can be chosen as an initial approximation; its average efficiency was only $83.2 \%$ while the constraint was $\langle\eta>>84 \%$. The total losses of the FRM after optimization decreased by 1.2 times. The average efficiency after optimization was $85.9 \%$, and the efficiency constraint was satisfied. In the initial design, the volume of demagnetized magnets was unacceptably high and equal to $0.21 \%$. After optimization, it was equal to $0.15 \%$, while the constraint was not more than $0.3 \%$. Thus, the conditions for demagnetization were met with a margin. The value of the parameter $A$, which describes the oscillations of the torque, was reduced by $4 \%$.

\section{Conclusions}

The cost of bonded magnets is lower compared with sintered magnets. Furthermore, in contrast with sintered magnets, bonded magnets are dielectric. Therefore, there is no need for segmentation of bonded magnets when using them in a motor, which leads to a lower motor price and a simpler manufacturing technology for a high-speed motor. However, bonded magnets have lower remanence and coercivity. In this study, the problem of developing a flux reversal motor (FRM) with bonded magnets was considered, in which the proposed FRM with bonded magnets has approximately the same efficiency as an FRM 
with sintered magnets [11]. In addition to this requirement, the peak-to-peak value of torque ripple (PPTR) is minimized and the minimum instantaneous torque value in two operating modes is maximized.

Due to the lower coercivity of bonded magnets, it is necessary to avoid their demagnetization in the optimized design. For this purpose, a procedure has been developed for the optimal design of a high-speed single-phase FRM with bonded magnets.

The main challenge in this work was the development of a single-phase flux reversal motor with an asymmetrical rotor which was introduced in [11], which has low torque ripple and no negative torque periods when applying bonded magnets, considering a new constraint on the volume of demagnetized magnets. The constraint must be taken into account to enable the use of bonded magnets for this motor. For this, in particular, the optimization criterion (2) with soft constraints was composed.

The optimization criterion was constructed in such a way so as to maximize the efficiency, reduce torque ripple, and reduce the volume of the demagnetized bonded magnets. The one-criterion Nelder-Mead method was applied in this work to optimize the FRM design. After the optimization, the total losses of the FRM decreased by 1.2 times. The demagnetization constraint was met with a margin. The torque oscillations $A$ were reduced by $4 \%$.

In future works, we plan to compare various optimization methods in the design of a single-phase flux reversal motor with an asymmetrical rotor and to manufacture and test an experimental prototype of the FRM.

Author Contributions: Conceptual approach, V.P. and V.D.; data curation, V.D. and V.K.; software, V.D. and V.P.; calculations and modeling, V.P., V.D. and V.K.; writing—original draft, V.P., V.D. and V.K.; visualization, V.D. and V.K.; review and editing, V.P., V.D. and V.K. All authors have read and agreed to the published version of the manuscript.

Funding: This research received no external funding.

Data Availability Statement: All data are contained within the article.

Acknowledgments: The authors thank the editors and reviewers for their careful reading and constructive comments.

Conflicts of Interest: The authors declare no conflict of interest.

\section{References}

1. Bentouati, S. Permanent magnet brushless dc motors for consumer products. In Proceedings of the 9th International Conference on Electrical Machines and Drives, Canterbury, UK, 1-3 September 1999; pp. 118-122. [CrossRef]

2. Lee, J.; Lee, E.; Kim, J. Design of the single phase SRM for the blower considering self-starting. In Proceedings of the 2005 International Conference on Electrical Machines and Systems, Nanjing, China, 27-29 September 2005; pp. 667-670. [CrossRef]

3. Dmitrievskii, V.; Prakht, V.; Pozdeev, A.; Klimarev, V.; Mikhalitsyn, A. Single-phase Flux reversal motor for Angular grinder. In Proceedings of the 8th IET International Conference on Power Electronics, Machines and Drives (PEMD 2016), Glasgow, UK, 19-21 April 2016; pp. 1-6. [CrossRef]

4. Ostovic, V. Performance comparison of U-Core and round-stator single-phase permanent-magnet motors for pump applications. IEEE Trans. Ind. Appl. 2002, 38, 476-482. [CrossRef]

5. Lee, W.; Han, D.; Sarlioglu, B. Comparative Performance Analysis of Reference Voltage-Controlled Pulse Width Modulation for High-Speed Single-Phase Brushless DC Motor Drive. IEEE Trans. Power Electron. 2017, 33, 4560-4568. [CrossRef]

6. Hu, H.-J.; Cao, G.-Z.; Huang, S.-D.; Wu, C.; Peng, Y.-P. Drive circuit-based torque-ripple suppression method for single-phase BLDC fan motors to reduce acoustic noise. IET Electr. Power Appl. 2019, 13, 881-888. [CrossRef]

7. Gieras, J. Design of high-speed permanent magnet machines. Przeglad Elektrotechniczny 2015, 95, 1-8. [CrossRef]

8. Zhang, Z.; Tang, X.; Wang, D.; Yang, Y.; Wang, X. Novel Rotor Design for Single-Phase Flux Switching Motor. IEEE Trans. Energy Convers. 2018, 33, 354-361. [CrossRef]

9. Chen, Y.; Chen, S.; Zhu, Z.Q.; Howe, D.; Ye, Y.Y. Starting Torque of Single-Phase Flux-Switching Permanent Magnet Motors. IEEE Trans. Magn. 2006, 42, 3416-3418. [CrossRef]

10. Dmitrievskii, V.; Prakht, V.; Kazakbaev, V.; Sarapulov, S. Optimal Design of a High-Speed Single-Phase Flux Reversal Motor for Vacuum Cleaners. Energies 2018, 11, 3334. [CrossRef]

11. Dmitrievskii, V.; Prakht, V.; Kazakbaev, V.; Golovanov, D. Optimum Design of High-Speed Single-Phase Flux Reversal Motor with Reduced Torque Ripple. Appl. Sci. 2020, 10, 6024. [CrossRef] 
12. Jeong, K.; Ahn, J. Design and characteristics analysis of a novel single-phase hybrid SRM for blender application. J. Electr. Eng. Technolo. 2018, 13, 1996-2003. [CrossRef]

13. Lukman, G.; Hieu, P.; Jeong, K.; Ahn, J. Characteristics analysis and comparison of high-speed $4 / 2$ and hybrid $4 / 4$ poles switched reluctance motor. Machines 2018, 6, 4. [CrossRef]

14. Dmitrievskii, V.; Prakht, V.; Kazakbaev, V. Novel Rotor Design for High-Speed Flux Reversal Motor. Energy Rep. 2020, 6, 1544-1549. [CrossRef]

15. Zhou, Y.; Zhou, L.; Hu, B.; Li, R. Design and performance analysis of permanent magnet flux-switching motors using segmental permanent magnets. IEICE Electron. Exp. 2019, 16, 1-6. [CrossRef]

16. Yamazaki, K.; Fukushima, Y. Effect of Eddy-Current Loss Reduction by Magnet Segmentation in Synchronous Motors with Concentrated Windings. IEEE Trans. Ind. Appl. 2011, 47, 779-788. [CrossRef]

17. Wills, D.; Kamper, M. Reducing PM eddy current rotor losses by partial magnet and rotor yoke segmentation. In Proceedings of the XIX International Conference on Electrical Machines-ICEM 2010, Rome, Italy, 6-8 September 2010; pp. 1-6. [CrossRef]

18. Kobayashi, M.; Morimoto, S.; Sanada, M.; Inoue, Y. Basic Study of PMASynRM with Bonded Magnets for Traction Applications. In Proceedings of the 2018 International Power Electronics Conference (IPEC-Niigata 2018-ECCE Asia), Niigata, Japan, 20-24 May 2018; pp. 2802-2807. [CrossRef]

19. Constantinides, S. Magnet Selection, Sintered \& Bonded NdFeB Magnets, Arnold Magnetic Technologies. 15-17 October 2003. Available online: https:/ / www.arnoldmagnetics.com/wp-content/uploads/2017/10/Magnet-Selection-ConstantinidesGorham-2003-psn-hi-res.pdf (accessed on 12 December 2020).

20. Tsunata, R.; Takemoto, M.; Ogasawara, S.; Watanabe, A.; Ueno, T.; Yamada, K. Development and evaluation of an axial gap motor with neodymium bonded magnet. In Proceedings of the 2016 XXII International Conference on Electrical Machines (ICEM), Lausanne, Switzerland, 4-7 September 2016; pp. 272-278. [CrossRef]

21. Borghi, C.; Casadei, D.; Cristofolini, A.; Fabbri, M.; Serra, G. Minimizing torque ripple in permanent magnet synchronous motors with polymer-bonded magnets. IEEE Trans. Magn. 2002, 38, 1371-1377. [CrossRef]

22. Ferraris, L.; Pošković, E.; La Cascia, D. Design optimization for the adoption of bonded magnets in PM BLDC motors. In Proceedings of the IECON 2014-40th Annual Conference of the IEEE Industrial Electronics Society, Dallas, TX, USA, 29 October-1 November 2014; pp. 476-482. [CrossRef]

23. Abad, V.; Sagredo, J.; Gonzalez, J. FEA Analysis and Optimization of Rotor Models in Permanent-Magnet Synchronous Motors fitted with Bonded Rare-Earth Magnets. Ren. Energy Power Qual. J. 2019, 17, 37-42. [CrossRef]

24. Cupertino, F.; Pellegrino, G.; Gerada, C. Design of synchronous reluctance machines with multiobjective optimization algorithms. IEEE Trans. Ind. Appl. 2014, 50, 3617-3627. [CrossRef]

25. Zăvoianu, A.; Bramerdorfer, G.; Lughofer, E.; Silber, S.; Amrhein, W.; Klementac, E. Hybridization of multi-objective evolutionary algorithms and artificial neural networks for optimizing the performance of electrical drives. Eng. Appl. Artific. Intell. 2013, 26, 1781-1794. [CrossRef]

26. Krasopoulos, C.; Beniakar, M.; Kladas, A. Robust Optimization of High-Speed PM Motor Design. IEEE Trans. Magn. 2017, 53, 1-4. [CrossRef]

27. Dmitrievskii, V.; Prakht, V.; Kazakbaev, V. IE5 Energy-Efficiency Class Synchronous Reluctance Motor with Fractional Slot Winding. IEEE Trans. Ind. Appl. 2019, 55, 4676-4684. [CrossRef]

28. Prakht, V.; Dmitrievskii, V.; Kazakbaev, V. Optimal Design of Gearless Flux-Switching Generator with Ferrite Permanent Magnets. Mathematics 2020, 8, 206. [CrossRef]

29. Bonded Magnets, Abbreviated Product List, Arnold Magnetic Technologies, 2013. Available online: https://www. arnoldmagnetics.com/wp-content/uploads/2017/10/Plastiform-Bonded-Magnets-Abbreviated-Product-List-11-11-13.pdf (accessed on 12 December 2020).

30. He, L.; Gilbert, M.; Johnson, T.; Pritchar, T. Conceptual design of AM components using layout and geometry optimization. Comput. Math. Appl. 2019, 78, 2308-2324. [CrossRef]

31. Non-oriented Electrical steel, Posco, product Catalogue. 2019. Available online: http://www.steel-n.com/e-sales/pdf/en/e_ electrical_pdf_NO_2020.pdf (accessed on 12 December 2020).

32. Nelder, J.; Mead, R. A Simplex Method for Function Minimization. Comput. J. 1965, 7, 308-313. [CrossRef]

33. Prakht, V.; Dmitrievskii, V.; Kazakbaev, V.; Sarapulov, S. Steady-state model of a single-phase flux reversal motor. In Proceedings of the IEEE 58th International Scientific Conference on Power and Electrical Engineering of Riga Technical University (RTUCON 2017), Riga, Latvia, 12-13 October 2017; pp. 1-5. [CrossRef] 